\title{
Principal component analysis on sewage sludge characteristics and its implication to dewatering performance with $\mathrm{Fe}^{2+}$ I persulfate-skeleton builder conditioning
}

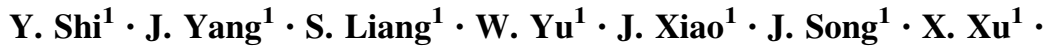

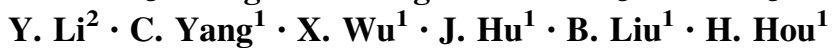

Received: 15 February 2016/Revised: 29 May 2016/Accepted: 28 June 2016/Published online: 12 July 2016

(C) Islamic Azad University (IAU) 2016

\begin{abstract}
Sludge samples taken from different sources and times may have different characteristics that could affect dewatering performance. In this study, 20 sludge samples from five wastewater treatment plants and different seasons in 1 year were characterized. Pearson correlation analysis indicated that solid content (SC), total suspended solid (TSS), polysaccharides and proteins contents had positive correlations with the capillary suction time (CST), whereas volatile suspended-solid/total suspended solid (VSS/TSS) exhibited negative correlations with CST. Moreover, no correlations between CST and specific resistance to filtration were found among these different sludge samples. The principal component analysis confirmed that only two group variables could represent most of the sludge characteristic parameters. The first set of variables represents the particulate nature of the biotic factors (SC, VSS/TSS, SCOD, TSS, polysaccharides and proteins), and the second set is the $\mathrm{pH}$. CST could not be a reasonable indicator of
\end{abstract}

Y. Shi and S. Liang authors have contributed equally to this work.

Electronic supplementary material The online version of this article (doi:10.1007/s13762-016-1064-6) contains supplementary material, which is available to authorized users.

\section{J. Yang}

jkyang@hust.edu.cn

1 School of Environmental Science and Engineering, Huazhong University of Science and Technology, Wuhan 430074, China

2 Universtar Science and Technology (Shenzhen) Co. Ltd., Shenzhen 518057, China dewaterability in sludge deep dewatering by $\mathrm{Fe}^{2+} / \mathrm{S}_{2} \mathrm{O}_{8}{ }^{2-}$ phosphogypsum composite conditioning. Furthermore, the results of diaphragm filter press dewatering showed that initial SC and VSS/TSS were the most dominant sludge characteristics affecting the solid content of dewatered cake $\left(R_{\mathrm{p}}=0.610, p=0.016 ; R_{\mathrm{p}}=-0.838, p=0.000\right.$, respectively) with $\mathrm{Fe}^{2+} / \mathrm{S}_{2} \mathrm{O}_{8}{ }^{2-}$-phosphogypsum composite conditioning. Results from this study suggest that dewatering performance is predictable by sludge characteristics parameters for $\mathrm{Fe}^{2+} / \mathrm{S}_{2} \mathrm{O}_{8}{ }^{2-}$-phosphogypsum conditioning.

Keywords Sewage sludge $\cdot$ Sludge characteristics $\cdot$ Sludge dewatering $\cdot$ Persulfate $\cdot$ Principal component analysis
Abbreviations
CST Capillary suction time
DE Dewatering efficiency
DS Dry solid
EPS Extracellular polymeric substances
LZ Longwangzui WWTP
PCA Principal component analysis
PN Proteins
PS Polysaccharides
SC Solid content
SCOD Soluble chemical oxygen demand
SL Sand Lake WWTP
S-P $\quad \mathrm{Fe}^{2+} / \mathrm{S}_{2} \mathrm{O}_{8}{ }^{2-}$-phosphogypsum
SPS Sodium persulfate
SRF Specific resistance to filtration
ST Sanjintan WWTP
TL Tangxun Lake WWTP
TSS Total suspended solids
VSS Volatile suspended solids
WWTP Waste water treatment plant
ZK Zhuankou WWTP 


\section{Introduction}

Sewage sludge is a by-product of wastewater treatment plants (WWTPs). Its handling/disposal represents $\sim 50 \%$ of total wastewater treatment operating costs, and poor dewatering efficiency is the bottleneck of all sludge disposal systems (García Becerra et al. 2010; He et al. 2015). Due to high compressibility and gel-like water retention capacity of the sludge that could be hardly removed water by simple mechanical compression, chemical conditioning is commonly incorporated firstly to improve its dewaterability ahead of mechanical compression (Mowla et al. 2013).

Selection of chemical conditioners is greatly dependent on sludge properties, such as sludge chemical compositions [extracellular polymeric substances (Jin et al. 2003; Mikkelsen and Keiding 2002)], physical properties [fractal dimensions (Vahedi and Gorczyca 2011), porosity (Thapa et al. 2009), osmotic pressure (Jin et al. 2003)] and rheological parameters [e.g., yield stress (Marinetti et al. 2010) and shear sensitivity (Dentel and Dursun 2009)]. Over the past decade, some sludge characteristics have been found to correlate with the sludge dewaterability. More recently, Skinner et al. (2015) proposed a model of filtration using sludge properties as inputs for quantification and comparison of dewaterability as the permeability and compressibility of sludge. In addition, moisture distribution ["free," "interstitial," "surface" or "bound" water (Lee 1996; Vesilind 1994)] is commonly accepted as the crucial factor influencing in dewatering performance. However, the water distribution concept alone is not sufficient to elucidate the dewaterability because some characterization methods of water distribution are not able to provide quantitative results and also relatively difficult to implement (Deng et al. 2011; Vaxelaire and Cezac 2004). Because the sludge properties vary with both production time and locations, it is insufficient to explain why difficulties to predict dewatering performance use water distribution. Therefore, it is essential for in-depth understanding on the correlations between sludge dewaterability and the main physicochemical characteristics of sludge conditioning and deep dewatering.

In recent years, Fenton and Fenton-like processes, as one group of advanced oxidation processes, have been widely investigated and proved to be an efficient chemical conditioning for sludge (He et al. 2015; Lu et al. 2003; Mo et al. 2015; Zhou et al. 2015). We have previously utilized $\mathrm{Fe}^{2+} / \mathrm{S}_{2} \mathrm{O}_{8}{ }^{2-}$ and/or phosphogypsum as sludge conditioner to efficiently breakdown sludge flocs, and further from skeleton structures for significantly improving the dewaterability, $45.7 \mathrm{wt} \%$ cake moisture content and $91.7 \%$ dewatering efficiency had been successfully achieved
(Shi et al. 2015a, b). Nevertheless, how sludge properties affecting dewaterability need to be fully characterized in order to achieve deep dewatering, especially sludge characteristics that vary with different sources.

The objective of this research was to provide a comprehensive study on the effects of dewaterability concerning various characteristics of different sludge sources and production times on the basis of $\mathrm{Fe}^{2+} / \mathrm{S}_{2} \mathrm{O}_{8}{ }^{2-}$-skeleton builder conditioning. The sludge characteristics including solid content (SC), $\mathrm{pH}$, total suspended solid/volatile suspended solid (TSS/VSS), TSS, soluble chemical oxygen demand (SCOD), polysaccharides and proteins were analyzed with Pearson correlation and principal component analysis (PCA). Principal factors associated with sludge characteristics and dewatering performance in the diaphragm filter press dewatering process were also proposed. This study proposed the dominant sludge characteristics that were able to evaluate the potential sludge dewaterability with $\mathrm{Fe}^{2+} / \mathrm{S}_{2} \mathrm{O}_{8}{ }^{2-}$-skeleton builder conditioning.

\section{Materials and methods}

\section{Sample collection and preparation}

Sludge samples were collected from five WWTPs in Wuhan, China, during a 1-year period, in April (named as I thereafter), August (named as II thereafter), November (named as III thereafter) and December (named as IV thereafter) in 2012-2013, as shown in Table S1. These five WWTPs, including Longwangzui (LZ), Sand Lake (SL), Sanjintan (ST), Tangxun Lake (TL) and Zhuankou (ZK), were chosen based on their geographic locations and the types of sewage treatment processes. The sample from LZ was mixed sludge with thickening process, while the samples from another four WWTPs were excess waste activated sludge without thickening process. All samples were stored at $4{ }^{\circ} \mathrm{C}$, and all the tests of each batch were completed within 3 days.

\section{Physicochemical analysis}

Solid content (SC), $\mathrm{pH}$, total suspended solid/volatile suspended solid (TSS/VSS) and soluble chemical oxygen demand (SCOD) were measured according to $\mathrm{CJ} / \mathrm{T}$ 221-2005 (China standard for municipal sludge analysis).

Proteins (PN) and polysaccharides (PS) are two major constituents of EPS. The supernatant was filtered using a $0.45-\mu \mathrm{m}$ pore size membrane filter (hydrophilic polyethersulfone) for the determination of PN and PS. PN was analyzed by the modified Lowry method, using bovine serum albumin as the standard (Frølund et al. 1996). 
PS was determined by the Anthrone method, using glucose as the standard (DuBois et al. 1956).

The SRF was calculated using the following formula (Eq. 1).

$\mathrm{SRF}=\frac{2 P A^{2} b}{\mu w}$

where $A$ is the area of the filter cake $\left(\mathrm{m}^{2}\right), P$ is the filtration pressure $\left(\mathrm{N} / \mathrm{m}^{2}\right), b$ is the slope of the plot of time over filtrate volume against filtrate volume $(\mathrm{s} / \mathrm{m}), b$ is the slope determined from the $t / V$ versus $V$ plot, ( $V$ is the volume of filtrate, $\mathrm{m}^{3}$; and $t$ is the filtration time, $\mathrm{s}, V$ as the $X$ axis, $t /$ $V$ as the $Y$ axis $)\left(\mathrm{s} / \mathrm{m}^{6}\right) . \mu$ is the viscosity of filtrate $\left(\mathrm{Ns} / \mathrm{m}^{2}\right)$, and $w$ is the sludge solids concentration $\left(\mathrm{kg} / \mathrm{m}^{3}\right)$.

The CST was measured using a 304 M CST instrument (Triton, UK). Slurry is poured into the 10 -mm-diameter tube resting on a piece of filter paper. The filtrate is extracted by capillary suction, and a cake is formed at the bottom of the tube. By measuring the distance of the filtrate that is required to travel along the paper as a function of time, the cake resistance can be determined.

\section{$\mathrm{Fe}^{2+} / \mathrm{S}_{2} \mathrm{O}_{8}{ }^{2-}$-phosphogypsum composite conditioner}

$\mathrm{Fe}^{2+}$-activated sodium persulfate (SPS) combined with pretreated phosphogypsum (referred as S-P composite conditioner) greatly enhanced sludge dewaterability (Shi et al. 2015a). The S-P conditioner including $100 \mathrm{mg} \mathrm{SPS} / \mathrm{g}$ DS (dry solid), $23.5 \mathrm{mg} \mathrm{Fe}^{2+} / \mathrm{g}$ DS and $300 \mathrm{mg}$ pretreatedtreated phosphogypsum/g DS. The $\mathrm{Fe}^{2+}$ solutions (40 wt $\%$ ) were prepared from $\mathrm{FeSO}_{4} \cdot 7 \mathrm{H}_{2} \mathrm{O}$ and distilled water. Raw phosphogypsum was collected from a phosphate fertilizer manufacturer in Guangxi, China. Hemihydrate $\left(\mathrm{CaSO}_{4} \cdot 0.5 \mathrm{H}_{2} \mathrm{O}\right)$ and a small amount of quartz were the main mineral phases in the pretreated phosphogypsum. It was pretreated at $150{ }^{\circ} \mathrm{C}$ for $2 \mathrm{~h}$ and then sieved using a $0.08 \mathrm{~mm}$ in size before used as the skeleton builder.

\section{Diaphragm filter pressing test}

Dewatering tests were performed using a laboratory-scale diaphragm filter press with six diaphragm plates (250 $\mathrm{mm} \times 250 \mathrm{~mm}$ plates, $10 \mathrm{~mm}$ depression). The schematic is shown in Fig. 1. The S-P composite conditioning was conducted as follows: First, SPS was added at a dose of $100 \mathrm{mg} / \mathrm{g}$ dry solid (DS) to a known amount of sludge in the conditioning tank and stirred at $300 \mathrm{rpm}$ for $10 \mathrm{~min}$. Afterward, $\mathrm{Fe}^{2+}$ was sequentially fed at $23.5 \mathrm{mg} / \mathrm{g}$ DS and stirred at $100 \mathrm{rpm}$ for $15 \mathrm{~min}$. Finally, $300 \mathrm{mg}$ thermal-treated phosphogypsum/g DS was added and kept stirring for $5 \mathrm{~min}$ at $100 \mathrm{rpm}$ to complete the conditioning process. CST and SRF of the conditioned sludge were tested to evaluate the filterability. Dewatering tests were conducted using the following procedure: The conditioned sludge was pumped into a sealed storage tank, in which the internal pressure was controlled by air pressure to feed the sludge to the diaphragm filter press. Then, the pressure was gradually increased to $0.8 \mathrm{MPa}$ until the discharge rate decreased, and the filtrate was collected and weighed. Last, all diaphragm plates were injected with compressed air at 1.2 $\mathrm{MPa}$ for about $15 \mathrm{~min}$ to squeeze the diaphragm plates for additional dewatering. After the pressure was released, the solid cakes inside each chamber were removed from the filter cloth and weighed. The solid content of the dewatered cake was determined after being dried at $105^{\circ} \mathrm{C}$ for $24 \mathrm{~h}$, and the dewatering efficiency (DE) was calculated according to Eq. 2 .

$\mathrm{DE}(\%)=\frac{M_{\text {filtrate }}-M_{\text {conditioners }}}{M_{\mathrm{cs}}} \times 100$

where $M_{\text {filtrate }}$ is the total mass of the filtrate $(\mathrm{kg}) ; M_{\text {condi- }}$ tioners is the water mass in the conditioners $(\mathrm{kg})$; and $M_{\mathrm{cs}}$ is the total mass of water in the conditioned sludge before dewatering $(\mathrm{kg})$.

\section{Statistical analysis}

Statistical analysis using univariate linear correlation was performed to evaluate the dominant factors. The Pearson's correlation coefficient $(R \mathrm{p})$ was used to evaluate linear correlations between two parameters. The $R \mathrm{p}$ is always between -1 and +1 , where -1 denotes a perfect negative correlation, +1 presents a perfect positive correlation and 0 indicates the absence of a relationship. Correlations were considered statistically significant at a $95 \%$ confidence interval $(p<0.05)$.

Principal components analysis (PCA) was conducted to determine the relationship among the sludge characteristic parameters (SC, pH, TSS/VSS, SCOD, PN, PS). This analytical method can extract the important information from a number of possibly correlated variables and represent them as a set of new uncorrelated and fewer variables, called principal components. It has been successfully applied to wastewater applications for monitoring and diagnostics of wastewater treatment processes (Tomita et al. 2002). Because the variables (SC, pH, TSS/VSS, SCOD, PN, PS) had different variances and units of measurements in this study, all data were normalized and scaled to equal unit variance (mean value of 0 and standard deviation of 1) prior to PCA. The components of the PCA were rotated by the varimax rotation. With this approach, the number of variables is reduced to a few axes (principal components) that represent more variance than randomly regressed variables. The statistical analysis above was all processed using the SPSS software (SPSS Inc., Chicago, USA). 
Fig. 1 Experimental setup for diaphragm filter dewatering in the laboratory scale

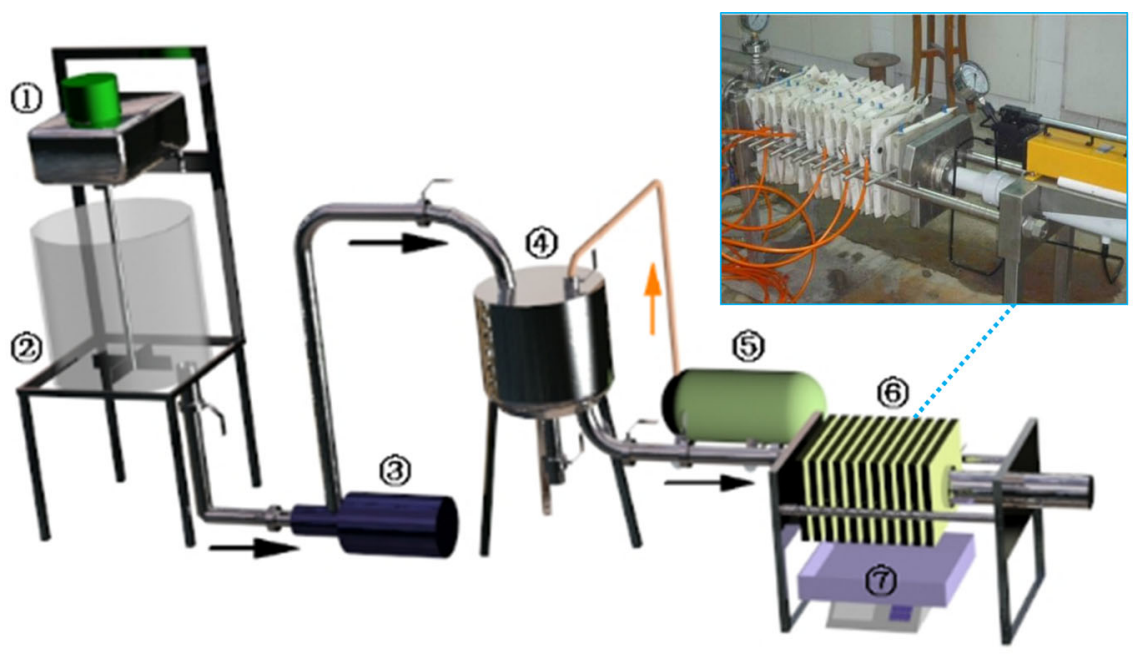

(1) Mixer motor (2) Conditioning tank (3) Screw pump (4) Storage tank (5) Air compressor (6) Diaphragm plate filter press (7) Electronic balance

\section{Results and discussion}

\section{Sludge characteristic parameters}

\section{Variations in sludge characteristics parameters}

A comprehensive comparison among the sludge characteristics from different WWTPs in four consecutive quarters is shown in Fig. 2. It distinctly indicated that samples from LZ and SL had higher solid content values (2.1-8.3 wt\%), whereas others exhibited lower solid content values, especially those from $\mathrm{TL}$ and $\mathrm{ZK}$ (0.6-1.7 wt\%) (Fig. 2a). In spite of the differences in wastewater treatment processes and the sludge types, TSS and solid content had a similar tendency (Fig. 2d). The pHs had insignificant variations, from 6.4 to 7.0, in all samples (Fig. 2b). In addition, it is clear that VSS/TSS values are narrowly distributed in LZ, SL and ST WWTPs, when compared to SCOD values that had a greater dispersion (Fig. 2c, e). Note that the VSS/TSS values in winter are higher than those of other seasons. Besides the variation in the biological treatment process and sludge storage duration, sediment was brought into WWTPs because of the deficient pipeline may also contribute to these differences.

The variations of PS and PN contents are similar to that of solid content (Fig. 2f, g). Most notably, there is no good correlation between the CST and SRF (Fig. 2h, i), which are in conflict with the common sense that a longer CST is along with a higher SRF. The CST values of the samples with lower solid content values were essentially similar. However, SRF was affected by several factors compared with solid content. Indeed, the CST tests provide a more accurate indication of filterability when the solid content values exceed $5 \mathrm{wt} \%$ as suggested by Lee and Hsu (1994). Therefore, CST as a sludge dewaterability indicator becomes less reasonable for the excess activated sludge of extremely higher water content of $>99 \mathrm{wt} \%$ without thickening treatment, such as the raw sludge samples from TL and ZK with lower solid content.

\section{Correlations between sludge characteristic parameters}

To facilitate statistical analysis, pearson's correlation coefficients $\left(R_{\mathrm{p}}\right)$ were calculated by statistically pairing the values of sludge properties. The results are summarized in Table 1.

Results of statistical analyses indicate that there are no good correlations between $\mathrm{pH}$ and the other characteristic parameters. The positive correlations between SC and TSS, SCOD, PS, PN $\left(R_{\mathrm{p}}=0.966, p=0.000 ; R_{\mathrm{p}}=0.700\right.$, $p=0.001 ; \quad R_{\mathrm{p}}=0.718, \quad p=0.001 ; \quad R_{\mathrm{p}}=0.835, \quad p=$ 0.000 , respectively) and a negative correlation between SC and VSS/TSS $\left(R_{\mathrm{p}}=-0.819, p=0.000\right)$ were found. This suggests that the sewage treatment processes influence sludge composition, as well as SC.

For dewaterability, the CST was found to be positively correlated with the initial SC, TSS, PS and PN $\left(R_{\mathrm{p}}=0.738, \quad p=0.000 ; \quad R_{\mathrm{p}}=0.689, \quad p=0.002\right.$; $R_{\mathrm{p}}=0.511, p=0.030 ; R_{\mathrm{p}}=0.559, p=0.016$, respectively) and negatively correlated with initial VSS/TSS $\left(R_{\mathrm{p}}=-0.576, p=0.012\right)$. The SRF was negatively correlated with the initial SC and TSS $\left(R_{\mathrm{p}}=-0.476\right.$, $p=0.046 ; R_{\mathrm{p}}=-0.559, p=0.016$, respectively) and not correlated with the initial VSS/TSS, PS and PN. 

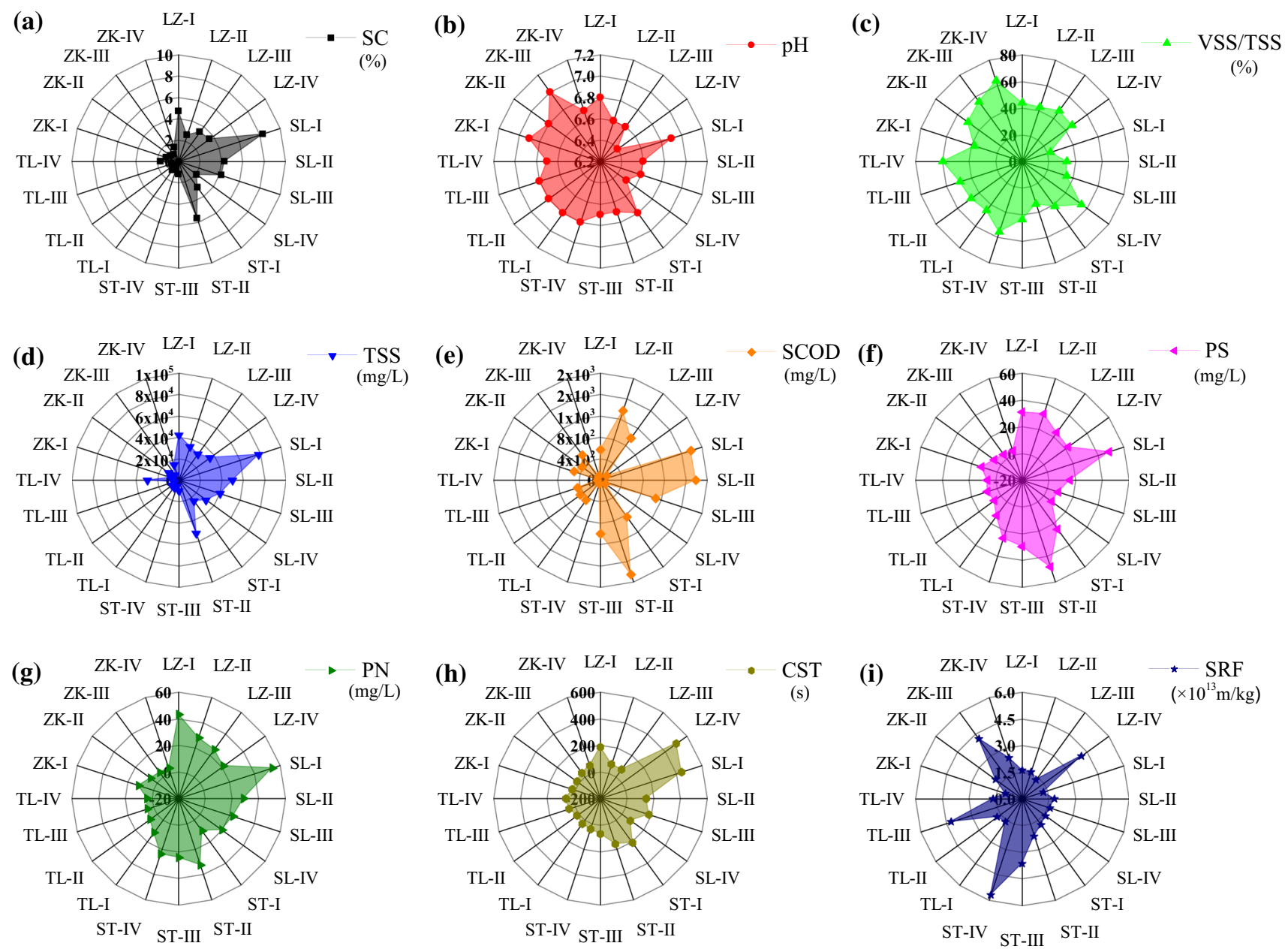

Fig. 2 Radar charts comparing the 20 sludge samples collected from five WWTPs (LZ, SL, ST, TL and ZK) in four quarters (I, II, III and IV) with regard to their basic sludge characteristics: a SC, b pH, c VSS/TSS, $\mathbf{d}$ TSS, e SCOD, f PS, $\mathbf{g}$ PN, h CST and i SRF

Although CST and SRF are two common parameters for estimating the filterability of sludge and are essential to determine the optimal conditioner doses, it was found that CST was not linearly correlated with SRF in this study. There are three plausible explanations for this result. First, CST value usually only correlate well with SRF for a specific suspended solid content, but not for biological sludge containing organic matter, such as flocs (Scholz 2005). Second, CST measurement is highly sensitive to properties such as SC and TSS, while SRF was found to be insensitive to some properties, such as biological activity, particles compressibility and temperature (Sawalha and Scholz 2010). The variation of the characteristics among different plants and times results in the inconsistent trend. Third, a more plausible explanation is that the interrelationships appeared to be multivariate and nondeterministic, depending on filterability, TSS and temperature (Sawalha and Scholz 2010). Consequently, identification of the primary factors that relate to dewatering performance becomes necessary.

\section{Principal component analysis}

Statistical method PCA could effectively reduce the multidimensional space into fewer components, while keeping the variability of the data set. PCA is utilized to group samples according to the sludge characteristics. In this study, the first principal component (PC1) was responsible for $66.49 \%$ of the total variance in the data sets (Supplementary material Table S2), and the second principal component (PC2) was responsible for another $16.90 \%$; thus, those two PCs accounted for $83.39 \%$ of the total variability.

The influence of each measured variable is given by its loading according to its score, which allowed a decision on the importance of the variables with regard to the 
Table 1 Pearson correlation analysis of the characteristics parameters of various raw sludge samples

\begin{tabular}{|c|c|c|c|c|c|c|c|c|c|}
\hline & $\mathrm{SC}$ & $\mathrm{pH}$ & VSS/TSS & TSS & SCOD & PS & $\mathrm{PN}$ & CST & SRF \\
\hline \multicolumn{10}{|l|}{$\mathrm{SC}$} \\
\hline$R \mathrm{p}$ & 1 & & & & & & & & \\
\hline \multicolumn{10}{|l|}{ Sig. (two-tailed) } \\
\hline \multicolumn{10}{|l|}{$\mathrm{pH}$} \\
\hline$R \mathrm{p}$ & -0.105 & 1 & & & & & & & \\
\hline Sig. (two-tailed) & 0.678 & & & & & & & & \\
\hline \multicolumn{10}{|l|}{ VSS/TSS } \\
\hline$R \mathrm{p}$ & $-0.819^{* *}$ & 0.003 & 1 & & & & & & \\
\hline Sig. (two-tailed) & 0.000 & 0.990 & & & & & & & \\
\hline \multicolumn{10}{|l|}{ TSS } \\
\hline$R \mathrm{p}$ & $0.966^{* *}$ & -0.221 & $-0.757^{* *}$ & 1 & & & & & \\
\hline Sig. (two-tailed) & 0.000 & 0.378 & 0.000 & & & & & & \\
\hline \multicolumn{10}{|l|}{ SCOD } \\
\hline$R \mathrm{p}$ & $0.700^{* *}$ & 0.050 & $-0.876^{* *}$ & $0.668^{* *}$ & 1 & & & & \\
\hline Sig. (two-tailed) & 0.001 & 0.843 & 0.000 & 0.002 & & & & & \\
\hline \multicolumn{10}{|l|}{ PS } \\
\hline$R \mathrm{p}$ & $0.718^{* *}$ & 0.020 & $-0.686^{* *}$ & $0.631^{* *}$ & $0.652^{* *}$ & 1 & & & \\
\hline Sig. (two-tailed) & 0.001 & 0.938 & 0.002 & 0.005 & 0.003 & & & & \\
\hline \multicolumn{10}{|l|}{$\mathrm{PN}$} \\
\hline$R \mathrm{p}$ & $0.835^{* *}$ & -0.099 & $-0.738^{* *}$ & $0.796^{* *}$ & $0.627^{* *}$ & $0.827^{* *}$ & 1 & & \\
\hline Sig. (two-tailed) & 0.000 & 0.695 & 0.000 & 0.000 & 0.005 & 0.000 & & & \\
\hline \multicolumn{10}{|l|}{ CST } \\
\hline$R \mathrm{p}$ & $0.738^{* * *}$ & -0.262 & $-0.576^{*}$ & $0.689^{* *}$ & 0.270 & $0.511^{*}$ & $0.559^{*}$ & 1 & \\
\hline Sig. (two-tailed) & 0.000 & 0.293 & 0.012 & 0.002 & 0.278 & 0.030 & 0.016 & & \\
\hline \multicolumn{10}{|l|}{ SRF } \\
\hline$R \mathrm{p}$ & $-0.476^{*}$ & 0.156 & 0.362 & $-0.559^{*}$ & -0.396 & -0.102 & -0.256 & -0.074 & 1 \\
\hline Sig. (two-tailed) & 0.046 & 0.537 & 0.140 & 0.016 & 0.103 & 0.686 & 0.305 & 0.771 & \\
\hline
\end{tabular}

* Correlation is significant at the 0.05 level (two-tailed)

** Correlation is significant at the 0.01 level (two-tailed)

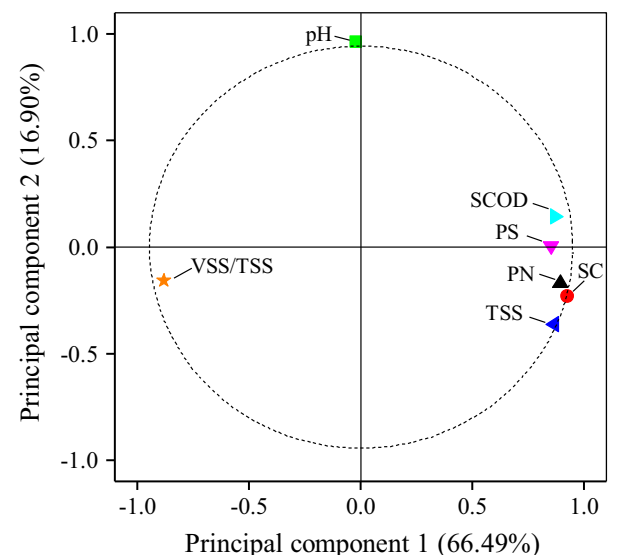

Fig. 3 Scatter plots of the first two principal component vectors for seven parameters of sludge property (principal component 1 vs. principal component 2) differences observed among the parameters. Figure 3 shows that all the initial variables could be well explained by the first two PCs since all points were found very close to the unit circle. All the seven parameters are classified into two groups. SC, SCOD, TSS, PN, PS and VSS/TSS were situated in the boundary of the graph with higher scores in PC1 and could be interpreted as "biotic factor." The variable with a higher influence on $\mathrm{PC} 2$ is $\mathrm{pH}$, which affected the adsorption and ionization equilibrium of the dispersed sludge particles. In general, it is considered that variables near each other are positively correlated, while those on the opposite sides of the origin are negatively correlated in the loading plots. SC, SCOD, TSS, PN and PS were plotted in similar positions, whereas VSS/TSS was plotted on opposite sides of the origin. Therefore, VSS/TSS was found to be negatively correlated with SC, and SC was positively correlated with SCOD, TSS, PN and PS. 
Considering the sludge liquid/solid phase, the primary properties of the liquid phase which influence sludge suspension property are $\mathrm{pH}$ and soluble organic content (e.g., PN and PS). The primary properties of the solid phase which influence sludge suspension property are the SC and flocculent nature of the solid. Therefore, the SC and VSS/ TSS are considered as the most important two parameters in influencing sludge dewaterability.

\section{Correlation between sludge dewatering performance and the characteristics parameters}

\section{Dewatering performance}

The dewatering performance from the diaphragm filter press tests is illustrated in Fig. 4. Each parameter is represented as a special pattern in a radar chart using responses of various types of sludge. The $\mathrm{pH}, \mathrm{CST}$ and VSS/TSS values of raw sludge and conditioned sludge clearly showed different patterns (Fig. $4 \mathrm{a}-\mathrm{c}$ ), and those values of conditioned sludge were decreased from 6.4-7.0, 15.4-502.4 s and 22.3-63.5 wt\% to 4.5-5.8, 11.6-111.9 s and 21.9-61.9 wt\%, respectively. Different initial SC results in a large difference in water volume at the same amount of dry solid and therefore a large variation in $\mathrm{pH}$ at a fixed S-P dosage for conditioning when using " $\mathrm{mg} / \mathrm{g}$ dry solid" as the dosage unit of conditioners.

In spite of the fact that CST value was directly affected by sludge solid concentration, CST reduction correlated strongly with the initial SC. Less than $55 \%$ of the CST reduction took place when solid content ranged from 0.6 to $2.1 \mathrm{wt} \%$, yet the $65-85 \%$ of CST reduction took place with solid content in the range of $2.6-8.3 \mathrm{wt} \%$. The value of VSS/TSS of the dewatered cake was slightly lower than the conditioned sludge. Dewatering efficiency (DE) was generally as high as $80 \%$, and the SC values of the dewatered cake were higher than $40.0 \mathrm{wt} \%$ when the initial SC was above $3.0 \mathrm{wt} \%$ (Fig. 4d). DE and SC of the dewatered cake in summer were generally higher than those of other seasons for a given WWTP. The reason for this was probably due to the higher VSS/TSS content and lower environmental temperature in winter that could affect the $\mathrm{Fe}^{2+} / \mathrm{S}_{2} \mathrm{O}_{8}{ }^{2-}$ reaction during sludge conditioning.

\section{Correlation of dewatering performance parameters}

The results of the Pearson's correlation of the major determining factors and dewatering performance are summarized in Table 2. The VSS/TSS of the dewatered cake was found to be positively correlated with the initial VSS/ TSS $\left(R_{\mathrm{p}}=0.899, p=0.000\right)$, while that was negatively correlated with the initial SC $\left(R_{\mathrm{p}}=-0.610, p=0.016\right)$. However, the $\mathrm{SC}$ of the dewatered cake was positively correlated with the initial SC $\left(R_{\mathrm{p}}=0.610, p=0.016\right)$ and negatively correlated with the initial VSS/TSS $\left(R_{\mathrm{p}}=-0.862, p=0.000\right)$. Additionally, there was no good negative correlation between CST or SRF of conditioned sludge and SC of dewatered cake. However, SRF of conditioned sludge was found to be negatively correlated
Fig. 4 Radar chart patterns for 20 sludge samples collected from five WWTPs (LZ, SL, ST, $\mathrm{TL}$ and $\mathrm{ZK}$ ) in four quarters (I, II, III and IV) with different parameters in S-P composite conditioning: a $\mathrm{pH}, \mathbf{b} \mathrm{CST}$, c VSS/TSS, d solid content (SC) of dewatered cake and dewatering efficiency (DE)
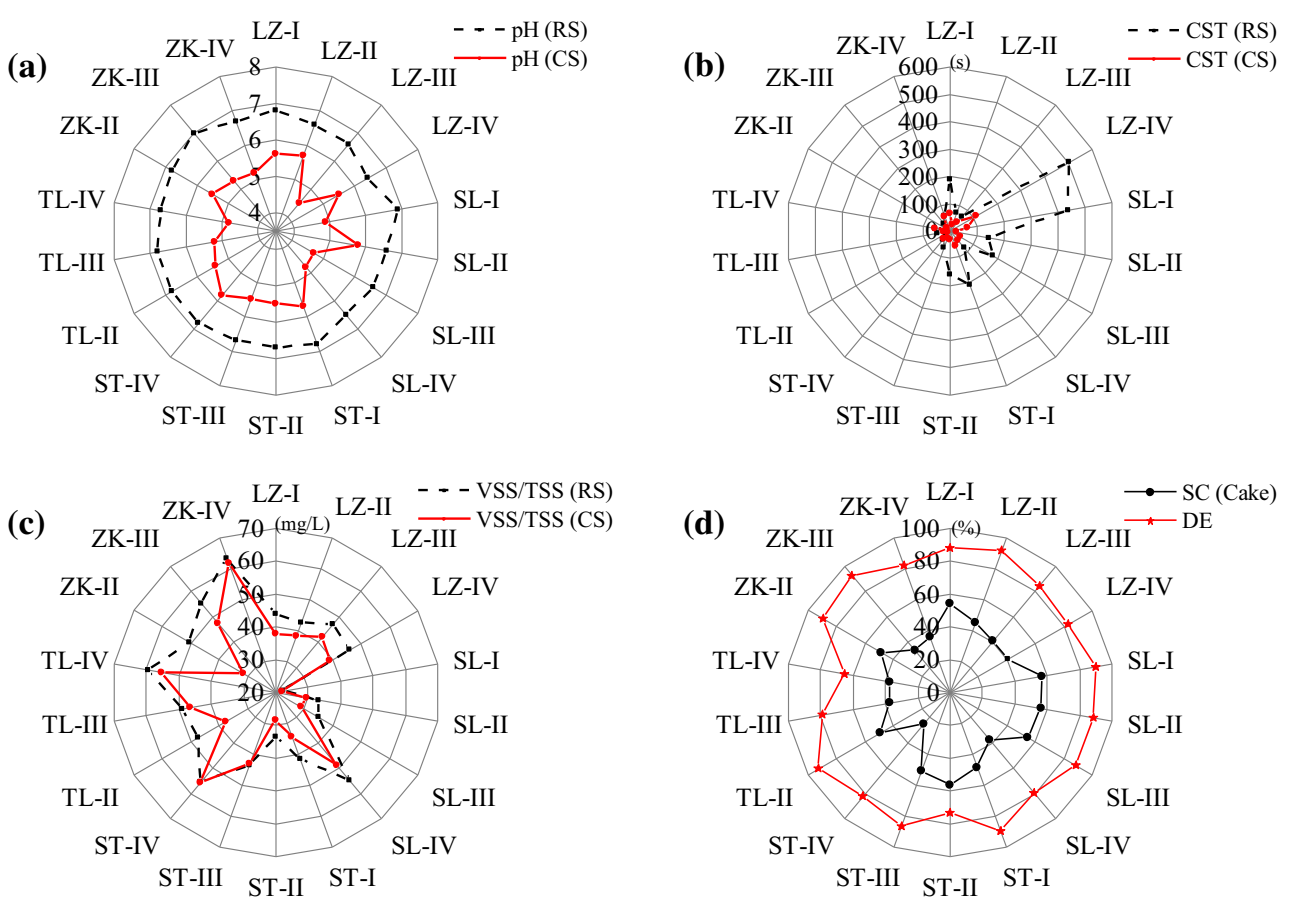
Table 2 Pearson correlation analysis of sludge characteristics and dewatering performance indicators

\begin{tabular}{|c|c|c|c|c|c|c|c|c|c|c|}
\hline & $\begin{array}{l}\text { CST } \\
\text { (RS) }\end{array}$ & $\begin{array}{l}\text { SRF } \\
\text { (RS) }\end{array}$ & $\begin{array}{l}\mathrm{SC} \\
(\mathrm{RS})\end{array}$ & $\begin{array}{l}\text { VSS/TSS } \\
\text { (RS) }\end{array}$ & $\begin{array}{l}\text { CST } \\
\text { (CS) }\end{array}$ & $\begin{array}{l}\text { SRF } \\
\text { (CS) }\end{array}$ & $\begin{array}{l}\mathrm{pH} \\
\text { (filtrate) }\end{array}$ & $\begin{array}{l}\text { VSS/TSS } \\
\text { (cake) }\end{array}$ & $\begin{array}{l}\text { SC } \\
\text { (cake) }\end{array}$ & $\mathrm{DE}$ \\
\hline \multicolumn{11}{|l|}{ CST (RS) } \\
\hline$R \mathrm{p}$ & 1 & & & & & & & & & \\
\hline \multicolumn{11}{|l|}{ Sig. (two-tailed) } \\
\hline \multicolumn{11}{|l|}{ SRF (RS) } \\
\hline$R \mathrm{p}$ & 0.145 & 1 & & & & & & & & \\
\hline Sig. (two-tailed) & 0.606 & & & & & & & & & \\
\hline \multicolumn{11}{|l|}{$\mathrm{SC}(\mathrm{RS})$} \\
\hline$R \mathrm{p}$ & $0.574 *$ & -0.396 & 1 & & & & & & & \\
\hline Sig. (two-tailed) & 0.025 & 0.144 & & & & & & & & \\
\hline \multicolumn{11}{|l|}{ VSS/TSS (RS) } \\
\hline$R \mathrm{p}$ & -0.346 & 0.252 & $-0.731 * *$ & 1 & & & & & & \\
\hline Sig. (two-tailed) & 0.206 & 0.364 & 0.002 & & & & & & & \\
\hline \multicolumn{11}{|l|}{ CST (CS) } \\
\hline$R \mathrm{p}$ & $0.818 * *$ & 0.157 & 0.314 & 0.161 & 1 & & & & & \\
\hline Sig. (two-tailed) & 0.000 & 0.576 & 0.255 & 0.567 & & & & & & \\
\hline \multicolumn{11}{|l|}{ SRF (CS) } \\
\hline$R \mathrm{p}$ & -0.091 & 0.112 & -0.304 & 0.426 & 0.269 & 1 & & & & \\
\hline Sig. (two-tailed) & 0.746 & 0.692 & 0.271 & 0.113 & 0.332 & & & & & \\
\hline \multicolumn{11}{|l|}{ pH (Filtrate) } \\
\hline$R \mathrm{p}$ & -0.020 & 0.410 & -0.218 & 0.013 & -0.159 & -0.116 & 1 & & & \\
\hline Sig. (two-tailed) & 0.944 & 0.129 & 0.435 & 0.964 & 0.571 & 0.681 & & & & \\
\hline \multicolumn{11}{|l|}{ VSS/TSS (Cake) } \\
\hline$R \mathrm{p}$ & -0.298 & 0.384 & $-0.610^{*}$ & $0.899 * *$ & 0.234 & $0.566^{*}$ & 0.028 & 1 & & \\
\hline Sig. (two-tailed) & 0.280 & 0.157 & 0.016 & 0.000 & 0.401 & 0.028 & 0.920 & & & \\
\hline \multicolumn{11}{|l|}{ SC (Cake) } \\
\hline$R \mathrm{p}$ & 0.188 & $-0.568^{*}$ & $0.610^{*}$ & $-0.838 * *$ & -0.224 & -0.265 & -0.084 & $-0.862 * *$ & 1 & \\
\hline Sig. (two-tailed) & 0.502 & 0.027 & 0.016 & 0.000 & 0.422 & 0.341 & 0.766 & 0.000 & & \\
\hline \multicolumn{11}{|l|}{$\mathrm{DE}$} \\
\hline$R \mathrm{p}$ & -0.089 & -0.003 & -0.164 & -0.263 & -0.405 & $-0.541^{*}$ & 0.148 & -0.367 & 0.210 & 1 \\
\hline Sig. (two-tailed) & 0.752 & 0.993 & 0.559 & 0.344 & 0.135 & 0.037 & 0.599 & 0.178 & 0.453 & \\
\hline
\end{tabular}

$R S$ raw sludge, $C S$ conditioned sludge

* Correlation is significant at the 0.05 level (two-tailed)

** Correlation is significant at the 0.01 level (two-tailed)

with $\mathrm{DE}\left(R_{\mathrm{p}}=-0.541, p=0.037\right)$. This result demonstrated that CST could not be a reasonable indicator for predicting $\mathrm{SC}$ of dewatered cake in deep dewatering by $\mathrm{Fe}^{2+} / \mathrm{S}_{2} \mathrm{O}_{8}{ }^{2-}$-phosphogypsum composite conditioning, while SRF may serve as a useful means for assessing the DE.

Compared with other factors, SC and VSS/TSS are the most important factors for dewatering performance, and the relationship between the $\mathrm{SC}$ of dewatered cake and the initial SC and VSS/TSS is shown in Fig. 5.

Figure 5 shows a high level of confidence as to the achievable $\mathrm{SC}$ of the dewatered cake compared to the initial SC and VSS/TSS. The relationship between the parameters is obvious, which has a strong relationship between the SC of the dewatered cake and the initial SC, as well as the initial VSS/TSS. It is consistent with Skinner's (2015) findings which showed that VSS/TSS parameter was a strong indicator of sewage sludge dewatering performance. The amount of VSS/TSS, on the one hand, directly affects the flocs composition and compressibility; on the other hand, in terms of EPS type and content account, VSS/TSS reflects a dominance of the volatile components in sludge during $\mathrm{Fe}^{2+} / \mathrm{S}_{2} \mathrm{O}_{8}{ }^{2-}$-phosphogypsum conditioning (Shi et al. 2015b). Moreover, higher initial SC also means less water, which would therefore result in an increase in the activation reaction rate due to 


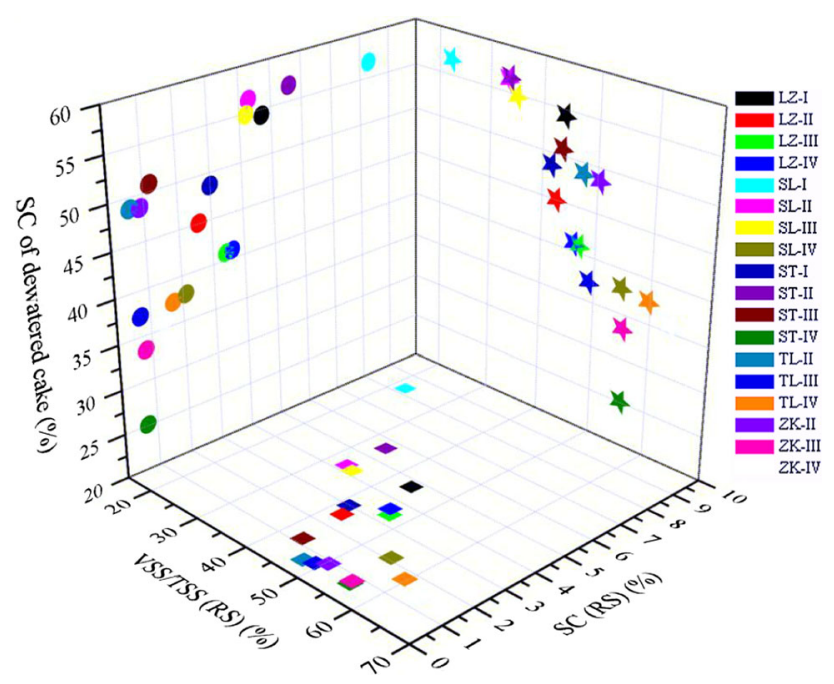

Fig. 5 Relationship among the solid content (SC) of dewatered cake, the initial SC and VSS/TSS from the diaphragm filter press tests

the conditioning system containing high concentrations of the reactants at a fixed S-P dosage.

Although a high SC of the dewatered cake is the comprehensive result of multiple factors such as SC, VSS/TSS and dewatering process, high SC and low VSS/TSS were beneficial for obtain a high SC of the dewatered cake with $\mathrm{Fe}^{2+} / \mathrm{S}_{2} \mathrm{O}_{8}{ }^{2-}$-phosphogypsum composite conditioning. Overall, the VSS/TSS and SC are the two dominating properties for the $\mathrm{Fe}^{2+} / \mathrm{S}_{2} \mathrm{O}_{8}{ }^{2-}$-phosphogypsum conditioning. Hence, it is easier to obtain a high solid content dewatered cake when its initial VSS/TSS was lower than $50.0 \mathrm{wt} \%$ and initial SC was higher than $3.0 \mathrm{wt} \%$. It should be noted that there is no agreed standard unit for dosages of various chemical conditioners, and different units were used for sludge conditioning, such as "mg/L" (Lu et al. 2003; Wang et al. 2009), "mg/g dry solid" (He et al. 2015; Liu et al. 2012; Mo et al. 2015), " $v / v$ " (Zhang et al. 2015) and "mmol/g VSS" (Zhen et al. 2012). In view of the importance of SC and VSS/TSS in sludge conditioning, an integrated dosage optimization method which based on the SC and VSS/TSS should be further considered for sludge conditioning.

\section{Conclusion}

Twenty sludge samples from five wastewater treatment plants over four consecutive quarters were characterized for their physicochemical properties. This paper developed the relationships between sludge characteristics parameters and dewatering performances and provided valuable information for S-P composite conditioning.
Pearson correlation analyses indicated that positive correlations existed among the initial SC and TSS, PS and PN, while negative correlations exhibited between initial $\mathrm{SC}$ and VSS/TSS. This suggests that the sewage treatment processes influence sludge composition. Meanwhile, the initial SC values were correlated positively with CST and negatively with SRF. The variation of the characteristics among different plants and times results in the inconsistent trend. CST could not be a reasonable indicator of dewaterability for the excess activated sludge of extremely higher water content in deep dewatering by S-P composite conditioning.

Initial VSS/TSS and SC are the two dominant properties with regard to the S-P composite conditioning. A high initial SC ( $>3 \mathrm{wt} \%)$ and low initial VSS/TSS $(<50 \mathrm{wt} \%)$ is conducive to obtain a high solid content $(>40 \mathrm{wt} \%)$ of the dewatered cake in the diaphragm filter press dewatering.

Acknowledgments The author would like to appreciate the financial support provided by the National Natural Science Foundation of China (51508214) and the Research Project of Chinese Ministry of Education (113046A) and Project of Innovative and Interdisciplinary Team of HUST (2015ZDTD027). The authors would also like to thank the Analytical and Testing Center of Huazhong University of Science and Technology for providing the experimental facilities and the five WWTPs for supplying the sludge samples.

\section{References}

Deng W, Li X, Yan J, Wang F, Chi Y, Cen K (2011) Moisture distribution in sludges based on different testing methods. J Environ Sci (China) 23(5):875-880

Dentel SK, Dursun D (2009) Shear sensitivity of digested sludge: comparison of methods and application in conditioning and dewatering. Water Res 43(18):4617-4625

DuBois M, Gilles KA, Hamilton JK, Rebers PA, Smith F (1956) Colorimetric method for determination of sugars and related substances. Anal Chem 28(3):350-356

Frølund B, Palmgren R, Keiding K, Nielsen PH (1996) Extraction of extracellular polymers from activated sludge using a cation exchange resin. Water Res 30(8):1749-1758

García Becerra FY, Acosta EJ, Allen DG (2010) Alkaline extraction of wastewater activated sludge biosolids. Bioresour Technol 101(18):6983-6991

He DQ, Wang LF, Jiang H, Yu HQ (2015) A Fenton-like process for the enhanced activated sludge dewatering. Chem Eng J 272:128-134

Jin B, Wilen BM, Lant P (2003) A comprehensive insight into floc characteristics and their impact on compressibility and settleability of activated sludge. Chem Eng J 95(1-3):221-234

Lee D (1996) Moisture distribution and removal efficiency of waste activated sludges. Water Sci Technol 33(12):269-272

Lee D-J, Hsu Y-H (1994) Use of capillary suction apparatus for estimating the averaged specific resistance of filtration cake. J Chem Technol Biotechnol 59(1):45-51

Liu H, Yang J, Shi Y, Li Y, He S, Yang C, Yao H (2012) Conditioning of sewage sludge by Fenton's reagent combined with skeleton builders. Chemosphere 88(2):235-239 
Lu MC, Lin CJ, Liao CH, Huang RY, Ting WP (2003) Dewatering of activated sludge by Fenton's reagent. Adv Environ Res 7(3):667-670

Marinetti M, Dentel SK, Malpei F, Bonomo L (2010) Assessment of rheological methods for a correlation to sludge filterability. Water Res 44(18):5398-5406

Mikkelsen LH, Keiding K (2002) Physico-chemical characteristics of full scale sewage sludges with implications to dewatering. Water Res 36(10):2451-2462

Mo R, Huang S, Dai W, Liang J, Sun S (2015) A rapid Fenton treatment technique for sewage sludge dewatering. Chem Eng J 269:391-398

Mowla D, Tran HN, Allen DG (2013) A review of the properties of biosludge and its relevance to enhanced dewatering processes. Biomass Bioenergy 58:365-378

Sawalha O, Scholz M (2010) Modeling the relationship between capillary suction time and specific resistance to filtration. J Environ Eng 136(9):983-991

Scholz M (2005) Review of recent trends in capillary suction time (CST) dewaterability testing research. Ind Eng Chem Res 44(22):8157-8163

Shi Y, Yang J, Mao W, Li Y, Xu X, Zhang H, Yu W, Li Y, Yang C (2015a) Influence of $\mathrm{Fe}^{2+}$-sodium persulfate on extracellular polymeric substances and dewaterability of sewage sludge. Desalin Water Treat 53(10):2655-2663

Shi Y, Yang J, Yu W, Zhang S, Liang S, Song J, Xu Q, Ye N, He S, Yang C, Hu J (2015b) Synergetic conditioning of sewage sludge via $\mathrm{Fe}^{2+} /$ persulfate and skeleton builder: effect on sludge characteristics and dewaterability. Chem Eng J 270:572-581
Skinner SJ, Studer LJ, Dixon DR, Hillis P, Rees CA, Wall RC, Cavalida RG, Usher SP, Stickland AD, Scales PJ (2015) Quantification of wastewater sludge dewatering. Water Res 82:2-13

Thapa KB, Qi Y, Clayton SA, Hoadley AF (2009) Lignite aided dewatering of digested sewage sludge. Water Res 43(3):623-634

Tomita RK, Park SW, Sotomayor OAZ (2002) Analysis of activated sludge process using multivariate statistical tools-a PCA approach. Chem Eng J 90(3):283-290

Vahedi A, Gorczyca B (2011) Application of fractal dimensions to study the structure of flocs formed in lime softening process. Water Res 45(2):545-556

Vaxelaire J, Cezac P (2004) Moisture distribution in activated sludges: a review. Water Res 38(9):2214-2229

Vesilind PA (1994) The role of water in sludge dewatering. Water Environ Res 66(1):4-11

Wang Y, Wei Y, Liu J (2009) Effect of $\mathrm{H}_{2} \mathrm{O}_{2}$ dosing strategy on sludge pretreatment by microwave $-\mathrm{H}_{2} \mathrm{O}_{2}$ advanced oxidation process. J Hazard Mater 169(1-3):680-684

Zhang W, Yang P, Yang X, Chen Z, Wang D (2015) Insights into the respective role of acidification and oxidation for enhancing anaerobic digested sludge dewatering performance with Fenton process. Bioresour Technol 181:247-253

Zhen G, Lu X, Zhao Y, Chai X, Niu D (2012) Enhanced dewaterability of sewage sludge in the presence of $\mathrm{Fe}(\mathrm{II})$ activated persulfate oxidation. Bioresour Technol 116:259-265

Zhou X, Wang Q, Jiang G, Liu P, Yuan Z (2015) A novel conditioning process for enhancing dewaterability of waste activated sludge by combination of zero-valent iron and persulfate. Bioresour Technol 185:416-420 